\title{
Study on Stress Distribution in Soft Ground Consolidated with Deep Cement Mixing Columns under Road Embankment
}

\author{
Tuan Anh Nguyen ${ }^{1, *}$, Thang Ngoc Nguyen ${ }^{2}$ \\ ${ }^{1}$ Faculty of Transportation Engineering, Ho Chi Minh City University of Transport, No 2 Vo Oanh St., Ward 25, Binh Thanh Dist., Ho \\ Chi Minh City, Viet Nam \\ ${ }^{2}$ Faculty of Civil Engineering, Tien Giang University, No 119 Ap Bac St., Ward 5, My Tho City, Tien Giang Province, Viet Nam
}

Received August 25, 2020; Revised November 12, 2020; Accepted November 29, 2020

\section{Cite This Paper in the following Citation Styles}

(a): [1] Tuan Anh Nguyen, Thang Ngoc Nguyen, "Study on Stress Distribution in Soft Ground Consolidated with Deep Cement Mixing Columns under Road Embankment," Civil Engineering and Architecture, Vol. 8, No. 6, pp. 1251 - 1265 , 2020. DOI: 10.13189/cea.2020.080609.

(b): Tuan Anh Nguyen, Thang Ngoc Nguyen (2020). Study on Stress Distribution in Soft Ground Consolidated with Deep Cement Mixing Columns under Road Embankment. Civil Engineering and Architecture, 8(6), 1251 - 1265. DOI: 10.13189/cea.2020.080609.

Copyright $\bigcirc 2020$ by authors, all rights reserved. Authors agree that this article remains permanently open access under the terms of the Creative Commons Attribution License 4.0 International License

\begin{abstract}
Soil consolidation using deep mixing method (DMM) is commonly used to protect soft ground in alluvial stratum in deltas such as Mekong Delta. In this study, the finite element method (FEM) using PLAXIS software is adopted to analyze the stress distribution on columns and ground base of the deep cement mixing (DCM) columns system combined with geotextiles in the consolidation of soft ground under road embankment in Tien Giang Province. With this method, the behavior of the DCM columns in soft ground treatment is examined by the distribution of stress and settlement of the DCM columns and soft soil layers. Simultaneously, the settlement of road base construction is monitored. The stress distribution on DCM columns and their settlement are also given from the analysis of FEM. The FEM models simulating the soft ground consolidated with DCM columns combined with geotextile under the road embankment in Tien Giang with the DCM columns of $0.6 \mathrm{~m}$ diameter, $11.2 \mathrm{~m}$ length and $1.0 \mathrm{~m}$ center - to- center spacing show the largest settlement of $0.120 \mathrm{~m}$ and the stability coefficient of 1.679 .
\end{abstract}

Keywords Montmorillonite, DCM, Soft Ground, Mekong Delta, Numerical Simulation

\section{Introduction}

The Mekong Delta has young tectonics of which over $90 \%$ of the area is soft soil. The regional economic development over recent years has promoted the integration of civil engineering technology to meet the economic needs. With the policy of developing infrastructure for the region, many traffic works, dams, warehouses and factories have been built. However, the constructions on soft ground often face a wide range of problems such as stability and subsidence compensation. A normal practice to solve this problem is to replace soft soil layer with a new one and make subsidence compensation [1]. Because the resources are limited and non-renewable, scientific, technological and engineering integration over recent years has brought new solutions to handle this problem with the goal of treating the foundation for a long-term stability, shortening treatment duration and reducing the amount of resources to compensate future subsidence.

Today, two popular DMMs are wet mixing method and dry mixing method. The principle of this method is to use a specialized device as a twist drill to direct its tip to the intended depth and at the same time, the soil is loosened and mixed with consolidation substances in downward or upward directions or both directions. Then a consolidated soil column is the product of the mixing of soft soil and 
consolidation substances [6].

The modern technology can help make DCM columns in various sizes. Deep mixers typically contain 1 to 4 mixing shafts. For multi-shaft mixer, these shafts are attached to rotating blades that rotate in opposite directions when mixing soil with cement to produce good quality columns. Column diameters may vary from $0.5 \mathrm{~m}$ to $2.0 \mathrm{~m}$. Recently, Japan has introduced big mixers with a number of mixing shafts up to 8 and is able to create columns with various areas of $1.0 \mathrm{~m}^{2}, 2.2 \mathrm{~m}^{2}$ and $5.7 \mathrm{~m}^{2}$ [4].

In Vietnam, lime-cement columns were introduced in early 80 's with Swedish technology. Then this technology has been applied in civil engineering to treat soft ground for constructions of water tanks, oil tanks and the irrigation works adopting technology of wet grouting for repair, crack proof and waterproof of drain bases, etc.

Japanese soft ground consolidation technology with DCM has been introduced and applied in transport industry during recent years. The most notable project was Can Tho airport in 2004, which adopted effectively DCM columns of $60 \mathrm{~cm}$ in diameter, $6 \mathrm{~m}$ in depth and $1 \mathrm{~m}$ at interval; the amount of cement accounted for $230 \mathrm{~kg}$ per $\mathrm{m}^{3}$ soft soil. Since then, this construction technology has been used regularly in Vietnam to protect soft ground for traffic works such as Ho Chi Minh City- Trung Luong Expressway, Thang Long Avenue and 5B National Highway, etc. [9].

Farouk and Shahien (2013) launched an experimental study using DCM columns to protect soft ground. The study results showed that the compressive strength of the cement-soil samples increased even when cement content was very low and the settlement of the footing was reduced by $80 \%$ depending on the quantity and length of the DCM columns [2].

Hormdee1and Jirawattana (2020) studied the load-bearing capacity and compressibility of the loess consolidated by compaction method and cement mortar mixture, the purpose of this study was to consider the load-bearing capacity and subsidence of Khon Kaen loess when it was compressed with and without cement. The lab and field test results showed that the tightness of the soil consolidated with cement increased by $95 \%$ against natural soil. This was because of the influence of density, initial moisture, added cement content and the curing time of the sample. The test results also stated that where the water content increased, the compressive strength of the sample decreased significantly and the compressibility of the sample increased sharply. For high cement content, the settlement decreased and the compressive strength of the sample increased critically [5].

Yemi Kehinde Ariye et al. (2020) carried out an experimental study for the consolidation of the road embankment by DCM columns from Papalanto to Sagamu about $43 \mathrm{~km}$ long in Ogun state, Nigeria. It was the road that was always in difficult conditions because of heavy trucks causing damage and subsidence. The solution was to use $5 \%$ of cement mixed with soil to increase the load capacity of the road embankment [24].

Moayed and Azini (2020) carried out a field load test to evaluate the results of the numerical model of shotcrete. The purpose of this study is to assess the results of the numerical model based on field static load test. The study result showed that the field test and modeling results were acceptable. It also stated that it was possible to use numerical models to study soft soil consolidation [20].

With current industrial revolution 4.0, Nguyen et al. (2020) also conducted a research on integrating information and communication into soft soil treatment with DCM columns. This research showed that when the DCM columns were applied into the ground, they were not able to be observed directly for their engineering process situations. The result was that inappropriate management of construction data and quality of DCM columns was experienced. By combining information and communication technology, a visualization system for the construction of DCM columns was developed, "3D Plile Viewer". The system consists of two functions: positioning guidance and visualization of construction information by using global positioning system, total station and inclinometer. Then, a 3D model of all information in the construction process such as depth, electrical current value, amount of mud, speed of rotation, etc., can be created and shared via internet [8].

The redistribution of stress on columns and ground depends on mutual impact between columns, soil, embankments, geotextiles and reinforcement layers (if applicable). The above-mentioned complicated impact is mainly due to the phenomenon of "Arching effect" in the ground. The determination of stress distribution in and below the ground consolidated with DCM columns is very important in the design of road embankments on soft ground. "The Arching effect is found to be the most common in soil both from laboratory and field tests" according to Terzaghi (1943) [23]. The results of field monitoring revealed that vertical load acting on column tips increased over time and it was the result of the arching effect on columns. The arching level is a function of the parameters of diameter, columns spacing, embankment height, and column over soft soil hardness ratio. The factors determining arching effect include height of embankment, column layout, shear strength of soil embankment and stiffness of column [15].

The studies on DCM columns in Vietnam first started in late 1980s. Typically, the research and application of scientific and technological progress 26-03-03-07 for DCM columns was led by Nguyen (1985), however such research was mainly conducted in laboratory and its results were only orientation [14].

In 2012, the Ministry of Science and Technology issued the National Standard for soft ground consolidation by the method of DCM columns [22]. This standard specifies technical requirements for surveying, testing, designing, 
constructing and accepting the DCM columns used to protect soft ground in the construction of light-load buildings and structures, embankments and protective slopes.

There have been so far a number of research topics and dissertations done at the Universities of Irrigation, Architecture, Construction, Transport, etc. Notable studies are described below:

The study by Tho (2011) on ensuring the stability of embankment on soft ground with the support of DCM columns [10] determines whether DCM column has similar structure to the hard bored pile surrounded by elastic ground and its tip on hard ground (vertical force acting on the pile is all transmitted to the hard ground) and Mindlin's theory of stress is used to (applied to the effect of force in the elastic space) build fs correlation with the force exerted in the soil around the column.

An (2012) studied some factors affecting the load-bearing capacity of DCM columns to protect soft ground [19]. The author believes that the settlement of the pile foundation is a complicated problem because there is a turbulence. Stress distribution upon availability of column is not known and load transmission mechanism in the column is not understood correctly. Therefore, the displacement of the load transmission mechanism is only approximately determined by semi-empirical, empirical method and compressive test methods.

The study by Dat (2013) applied chemical grouting technology to protect the dyke in Ha Nam Province. The study covered many new treatment technologies where they took in account high-pressure jet grouting technology that grouted cement in the soil to enhance the waterproofing effect of the dyke [12].

Hung (2014) from the University of Transport studied solutions to improve the effectiveness of soft soil treatment with DCM columns in the construction of embankments on soft ground. The software Plaxis V8.2 allows investigating on numerical model regarding variation of deformation (settlement) in various geological conditions, soft soil thickness and column sizes [16].

The study by Thang (2017) titled "Influence of Montmorillonite mineral on compressive strength of DCM columns " focused on analyzing the effect of MMT content on the compressive strength of soil-cement samples by unidirectional confined compressive test in combination with X-ray analysis method. The samples were cured in freshwater medium with curing duration of 7, 14 and 28 days. The test was performed on the samples of soil-cement made from Kaolinite clay with $20 \%$ cement, $80 \%$ moisture and the MMT content varying from $0 \%, 3.3 \%$, and $6.5 \%$ to $9.8 \%[11]$.

Generally, the authors have the same study subjects but different approaches and methods. This study has certain contributions to computational theories.

\section{Materials and Methods}

For deep mixing treatment designed to satisfy the feasible, economic and long-term requirements and withstand the impacts and influences during construction and operation, which means that it meets the conditions of extreme and the limit states of use, its design is normally made in iterative approach, in which the results of multiple test methods are an important aspect. The preliminary design is based on laboratory sample results. The correlation of unconfined compressive strength between the field column sample and laboratory sample can be chosen empirically from 0.2 to 0.5 depending on soil type and mixing ratio.

The method used is to study theories about the solution of consolidation with DCM columns in combination with the geotextiles under elevated embankment. These theories cover stress distribution and deformation in soft ground reinforced with DCM columns that are combined with geotextiles $[13,18]$.

Based on geotechnical data, loads, theoretical basis and related references [3], the author used Plaxis V8.2 software to analyze and assess the case of the DCM column group under the pressure of the upper embankment.

The failure model of the system is the soft ground (causing subsidence to the tip of the column or sliding to the soft ground around the DCM column). In practice, DCM columns are usually arranged in groups and in most of cases, the behavior of a single column is different from that of a group of columns, but it is often allowed to calculate the load which a single column carries. Evaluation of stability of the column according to limit state 1: the calculated load is determined based on an investigation of either shear failure or settlement failure (the minimum value of the limit load divided by the safety coefficient and the load corresponding to allowable settlement of the ground under the column). For the column under the impact of vertical loads, because the column is hard, the limit load $\mathrm{Q}_{\mathrm{gh}}$ thereof is determined by the limit resistance force of the column tip $Q_{p}$ (determined when the ground under the column fails) and lateral friction $Q_{f}$ (determined when sliding occurs between the ground and the column).

It should be noted that the determination of the ultimate limit value taking into account the failure of the soil under the column tip is calculated as the limit problem of shallow foundation. Determination of the shear friction force $f_{s}$ is calculated from the Coulomb soil sliding failure conditions. The determination of the soil-column strength $c_{a}, \varphi_{a}$ ) and the horizontal pressure of the soil acting on the column are complicated and there are many different points of view.

\subsection{Materials}

\subsubsection{Geological conditions}

In general, the ground surface is characterized by new alluvial to be rich in clay mud and organics, so it is 
relatively low in respect of topography and poorly loadresistant in respect of geology, which requires much compaction and protection in process of construction.

To obtain data on the properties of natural soils, a $30 \mathrm{~m}$ borehole was prepared in Chau Thanh district, Tien Giang province, Vietnam [7]. The testing results to determine the physical- mechanical properties of the soil layers are shown in Table 1.

The analysis and generalization of physical-mechanical properties from the data obtained from the borehole showed the strata of the boring position are divided into the following layers:

Layer 1: Clay mixed with little sand of dark gray-brown color, flowing state, medium plasticity; $9.8 \mathrm{~m}$ thick.

Layer 2: Clay mixed with a little sand of white-spotted gray-brown color, hard plasticity state, medium plasticity; $7.5 \mathrm{~m}$ thick.

Layer 3: Fine-grained sand in yellow-gray color, poorly tight condition; $2.6 \mathrm{~m}$ thick.

Layer 4: Clay mixed with a little sand of gray-yellow and white-gray color, semi-hard state, medium plasticity; $8.7 \mathrm{~m}$ thick.

\subsubsection{Calculation model in plaxis}

The calculation model is a road embankment with soft soil layers: The ground has 4 layers of soils including 11.2 $\mathrm{m}$ of soft clay, $7.5 \mathrm{~m}$ of sandy clay, $2.6 \mathrm{~m}$ of fine sand and $8.7 \mathrm{~m}$ of tight clay; above the soil layers, the road of $5 \mathrm{~m}$ high embankment is located as shown in the Fig.1.

When an analysis of two-dimensional finite element is made, it is possible to use plane strain model and axial symmetry model at the same time. In this study, the road embankment located on soft ground can be considered as a strap footing for calculation, so the road embankment will be simulated according to the plane strain model.

To simulate the soil layers, a triangular 6-node or 15 -node element is used to create a plane model for calculation. The 6-node triangular element is the default option for a 2-dimensional analysis. It provides an interpolation as two for displacement. The element hardness matrix is estimated by the integration of the sum of the three Gauss stress points. Whereas, the 15 -node triangular element has sequential interpolation and it is estimated by the integration of the sum of 12 stress points.

Table 1. Physical-mechanical properties of soil layers

\begin{tabular}{|c|c|c|c|c|}
\hline Physical-mechanical properties & Layer 1 & Layer 2 & Layer 3 & Layer 4 \\
\hline Water content, $\mathrm{W}(\%)$ & 71.24 & 30.14 & 25.65 & 26.53 \\
\hline Wet unit weight, $\gamma_{\mathrm{w}}\left(\mathrm{kN} / \mathrm{m}^{3}\right)$ & 15.62 & 19.12 & 19.35 & 19.63 \\
\hline Dry unit weight, $\gamma_{\mathrm{d}}\left(\mathrm{kN} / \mathrm{m}^{3}\right)$ & 9.12 & 14.69 & 15.40 & 15.51 \\
\hline Initial void ratio, $\mathrm{e}_{0}$ & 1.901 & 0.832 & 0.729 & 0.736 \\
\hline Liquid Limit, LL (\%) & 64.04 & 43.25 & - & 44.40 \\
\hline Plastic Limit, PL (\%) & 30.82 & 22.83 & - & 23.28 \\
\hline Liquidity index, IL(\%) & 1.22 & 0.36 & - & 0.15 \\
\hline Total deformation module, $\mathrm{E}_{01-2}\left(\mathrm{kN} / \mathrm{m}^{2}\right)$ & 508 & 2402 & 8278 & 2713 \\
\hline Cohesive, $\mathrm{c}\left(\mathrm{kN} / \mathrm{m}^{2}\right)$ & 8.8 & 11 & 8.8 & 38.2 \\
\hline Friction angle, $\varphi$ & $3^{0} 14$ & $5^{0} 58^{\prime}$ & $27^{0} 35^{\prime}$ & $15^{0} 15^{\prime}$ \\
\hline \multicolumn{5}{|l|}{ \%particle accumulation } \\
\hline$<4.75 \mathrm{~mm}(\%)$ & $100 \%$ & $100 \%$ & $100 \%$ & $100 \%$ \\
\hline$<2.00 \mathrm{~mm}(\%)$ & $100 \%$ & $100 \%$ & $100 \%$ & $100 \%$ \\
\hline$<0.425 \mathrm{~mm}(\%)$ & $100 \%$ & $100 \%$ & $95.5 \%$ & $100 \%$ \\
\hline$<0.075 \mathrm{~mm}(\%)$ & $100 \%$ & $94.5 \%$ & $34.2 \%$ & $95.8 \%$ \\
\hline$<0.002 \mathrm{~mm}(\%)$ & $44.1 \%$ & $32.1 \%$ & $6.0 \%$ & $33.6 \%$ \\
\hline
\end{tabular}



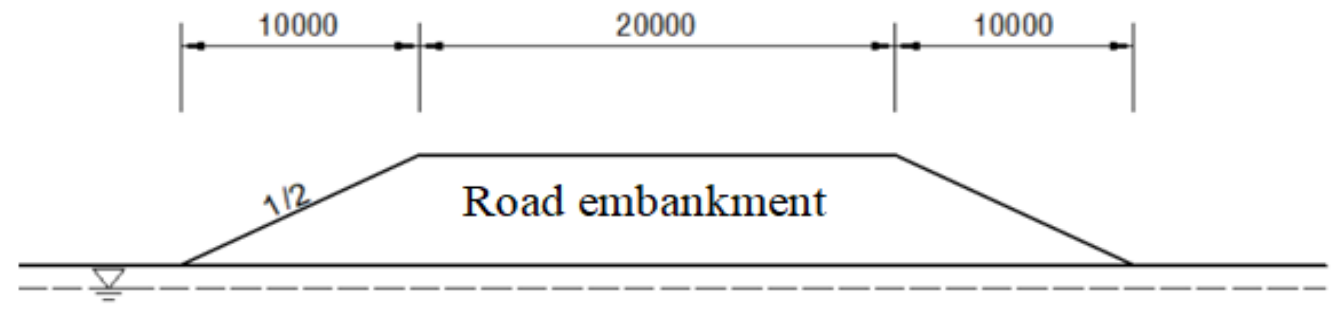

Layer $1-\mathrm{CH}$

Layer 2-CL2

Layer 3-SM

Layer 4-CL2

Figure 1. Cross section of road embankment on soft ground

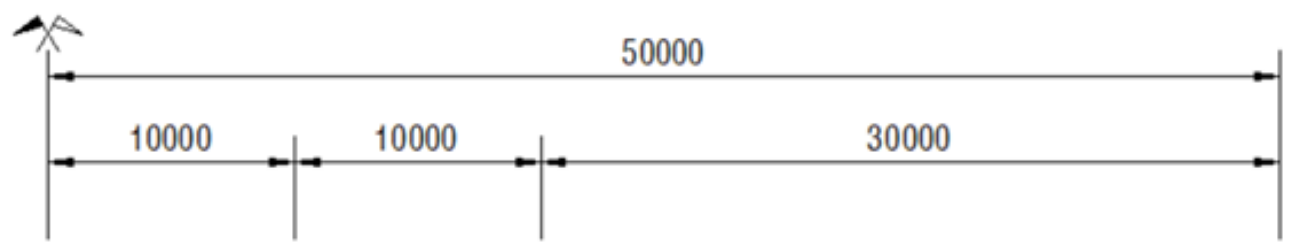

$20 \mathrm{kN} / \mathrm{m} 2$
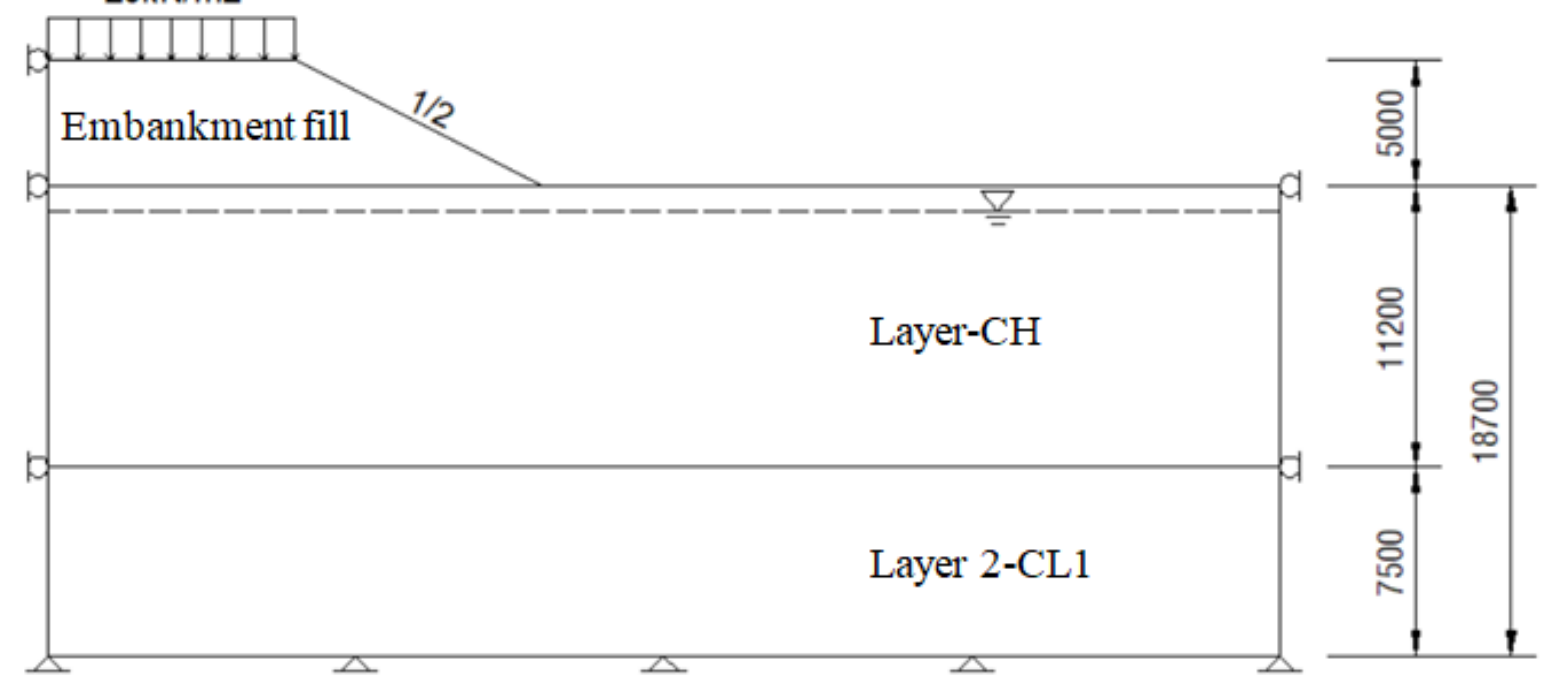

Figure 2. The soft ground is not consolidated

2.1.3. The case where the ground is not consolidated

The case where the ground is not consolidated is simulated in Figs. 2 and 3. The model of the finite element problem is simulated in Plaxis as shown in Figure 3, which contains untreated soft soil layers and the embankment of the roadbed. 


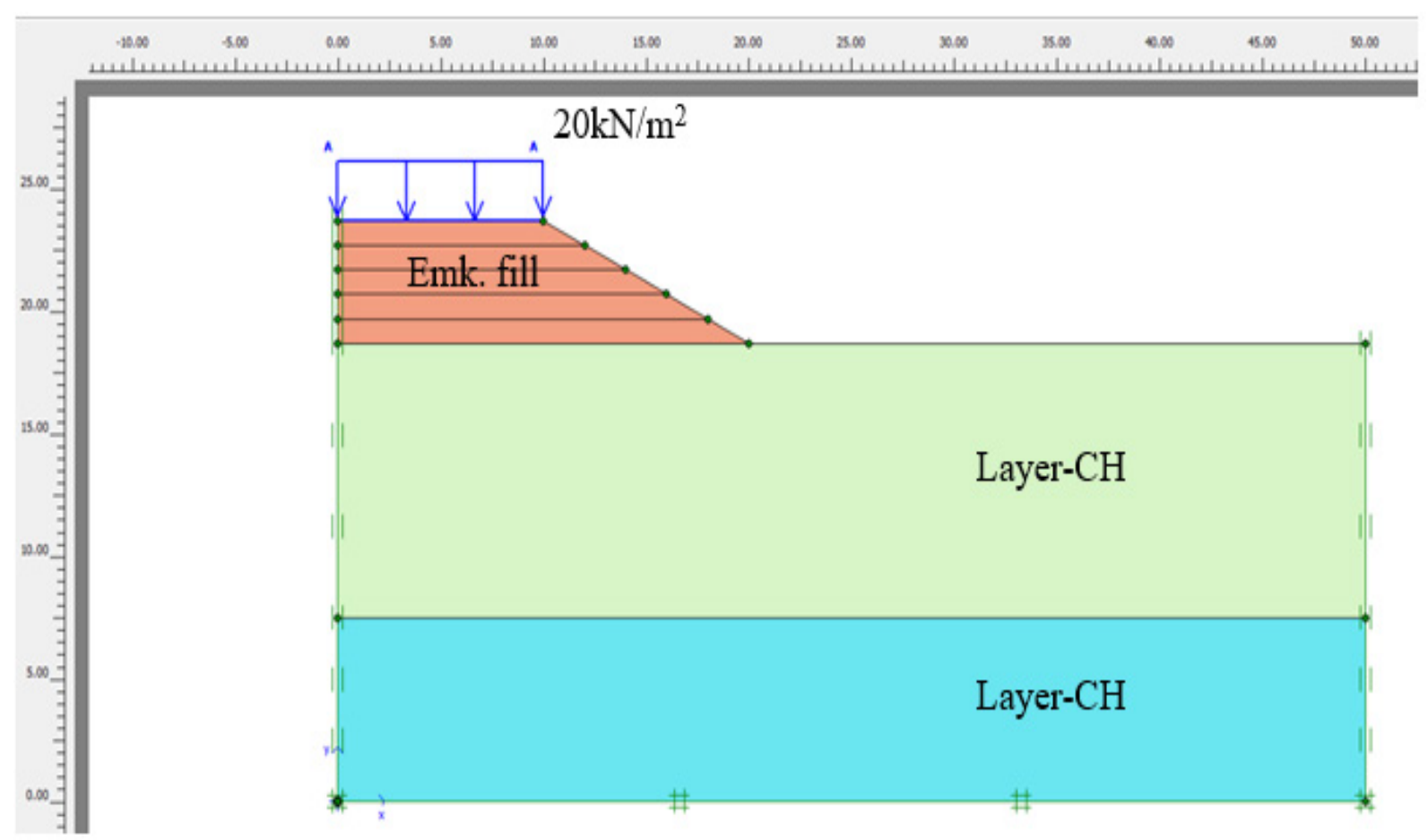

Figure 3. The model of finite element of the un-consolidated soft ground

2.1.4. The case where the soft ground is consolidated with DCM columns combined with geotextiles

The soft ground which is consolidated with DCM columns of $0.6 \mathrm{~m}$ in diameter, $11.2 \mathrm{~m}$ in length and $1.0 \mathrm{~m}$ in center to center spacing combined with geotextiles is simulated in Figs. 4 and 5. The roadbed is filled in layers in accordance with construction schedule, followed by the loads of vehicle operations.
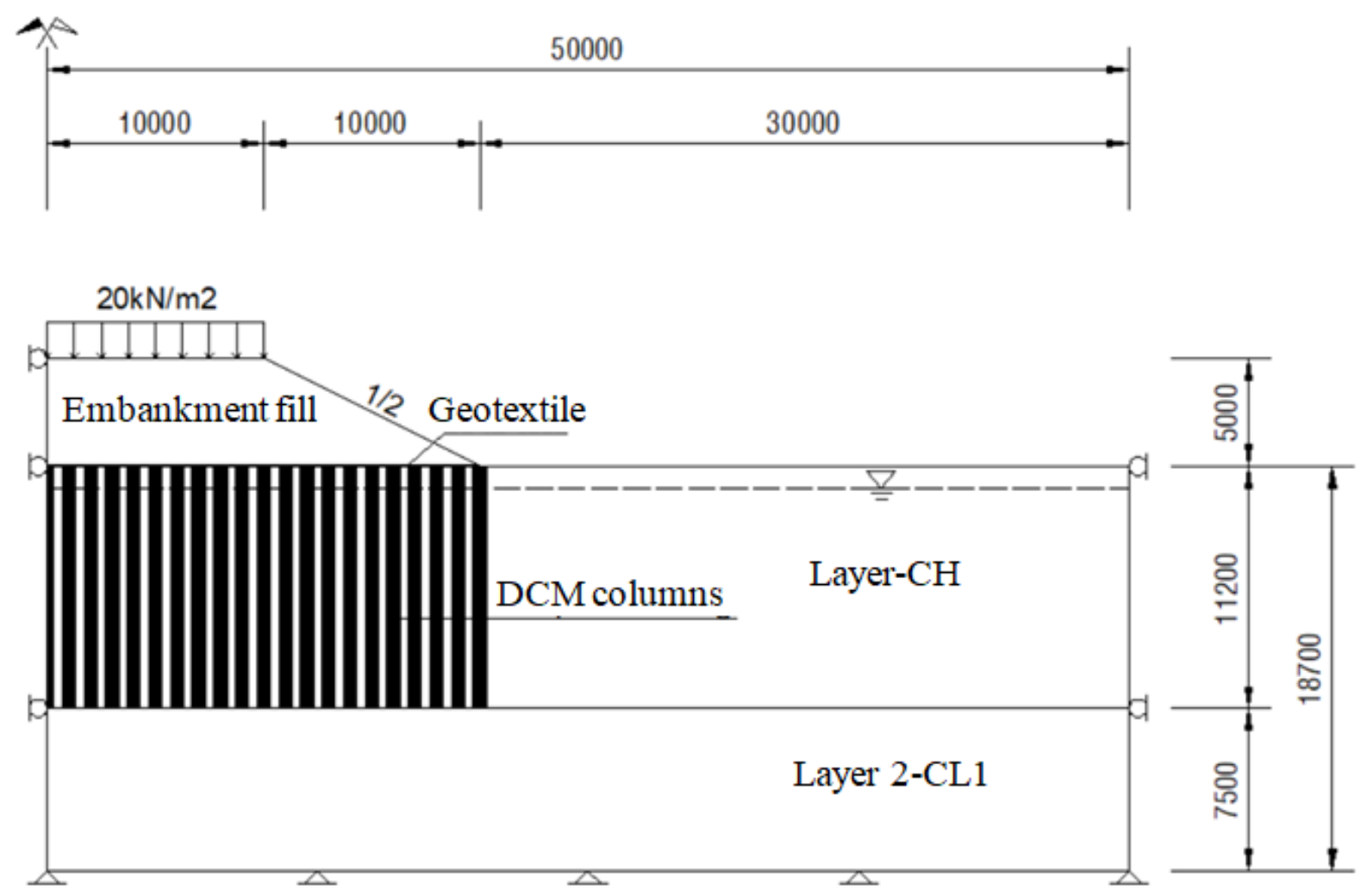

Figure 4. The soft ground is consolidated with DCM columns combined with geotextile 


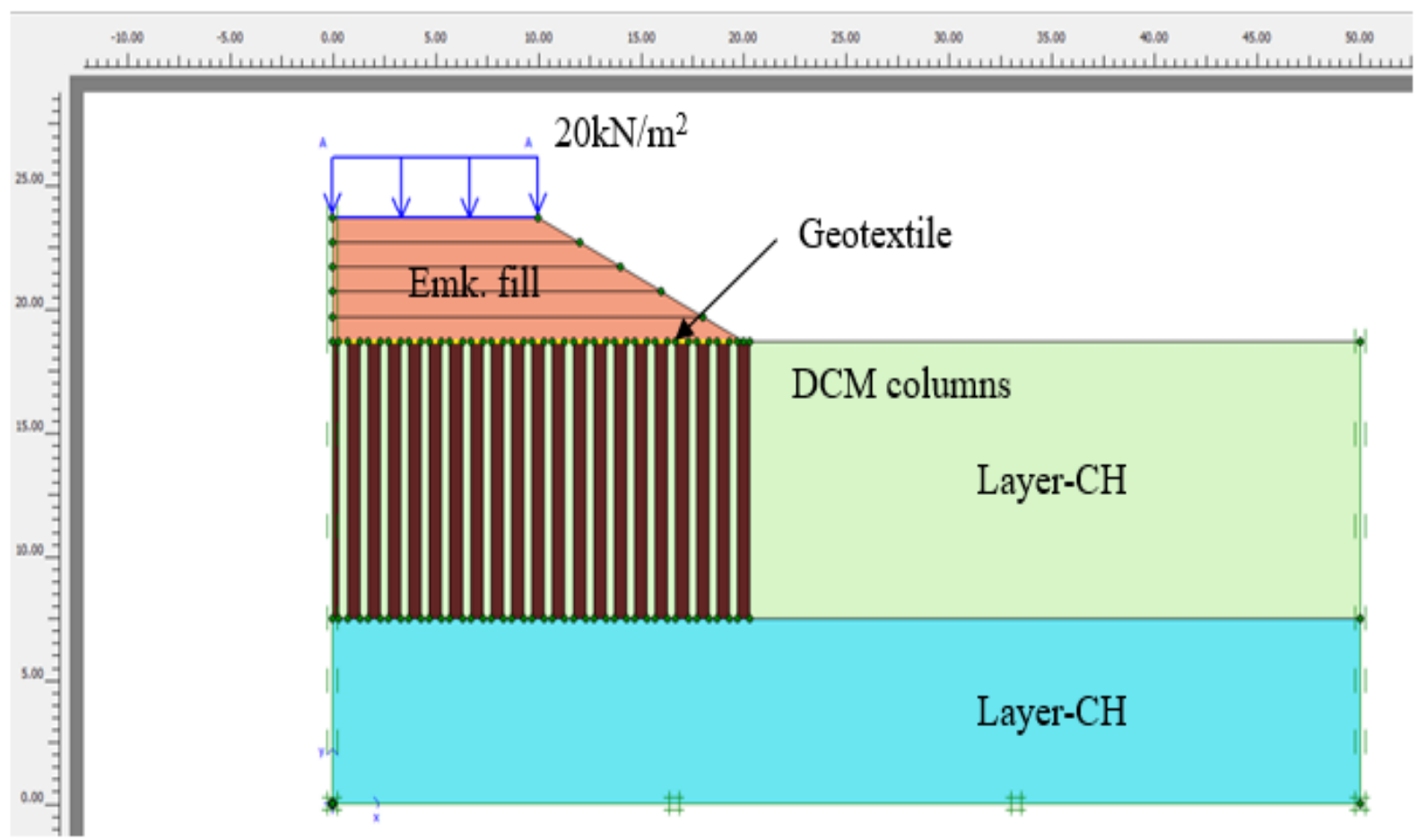

Figure 5. The model of finite element of the soft ground consolidated with DCM columns combined with geotextiles

\subsubsection{Boundary conditions}

Standard fixities format is utilized to register boundary conditions. Create limit conditions: Click the corresponding Standard fixities button on the toolbar. Plaxis automatically affects a set of common boundary conditions in the geometry model. These conditions are the following generated rules:

The vertical structures where the $\mathrm{x}$ coordinate is equal to the lowest or highest value in the model obtain a horizontal restraining $\left(\mathrm{u}_{\mathrm{x}}=0\right)$.

The horizontal structures where the y coordinate is equal to the lowest or highest value in the model obtain a full restraining $\left(\mathrm{u}_{\mathrm{x}}=\mathrm{u}_{\mathrm{y}}=0\right)$.

The standard restraining is used as a convenience and the fastest choice.

\subsubsection{Material characteristics registration}

Plaxis accepts soil models including Linear Elastic model (LE), Mohr-Coulomb model (MC), Hardening Soil model (HS), Soft Soil Creep model (SSC) and User Defined model (UD).

Among all the above models, the Mohr - Coulomb model is chosen to describe the actual properties of the soil and the computational applicability of Version 8.2. This is the ideal plastic-elastic model with 5 basic soil parameters: Young's modules (E), Poisson's ratio (v), Cohesion (c), Frictional angle $(\varphi)$ and Dilatancy angle $(\psi)$. Normally, all model parameters simulate the effective stress state of the soil. An important property of soil is the existence of pore water pressure. The effects of pore water pressure are divided into 3 types of behaviors in the software: drained behavior, un-drained behavior and non - porous behavior.
The parameters of soil layers are shown in Table 2.

Table 2. Parameters of soil layers in Plaxis model

\begin{tabular}{|c|c|c|c|}
\hline Parameters & Layer 1 & Layer 1 & Emb. fill \\
\hline Material model & $\begin{array}{c}\text { Mohr - } \\
\text { Coulomb }\end{array}$ & $\begin{array}{c}\text { Mohr - } \\
\text { Coulomb }\end{array}$ & $\begin{array}{c}\text { Mohr - } \\
\text { Coulomb }\end{array}$ \\
\hline Type of behavior & Un-drained & Un-drained & Drained \\
\hline $\begin{array}{c}\text { Unit weight } \gamma_{\text {unsat }} \\
\left(\mathrm{kN} / \mathrm{m}^{3}\right)\end{array}$ & 15.62 & 19.12 & 18.00 \\
\hline $\begin{array}{c}\text { Saturated unit weight } \\
\gamma_{\text {sat }}\left(\mathrm{kN} / \mathrm{m}^{3}\right)\end{array}$ & 15.67 & 19.23 & 20.00 \\
\hline $\begin{array}{c}\text { Horizontal } \\
\text { permeability } \\
\mathrm{k}_{\mathrm{x}}(\mathrm{m} / \text { day })\end{array}$ & $10^{-6}$ & $10^{-5}$ & $10^{-3}$ \\
\hline $\begin{array}{c}\text { Vertical permeability } \\
\mathrm{k}_{\mathrm{y}}(\mathrm{m} / \text { day })\end{array}$ & $10^{-6}$ & $10^{-5}$ & $10^{-3}$ \\
\hline $\begin{array}{c}\text { Young's modules, } \mathrm{E} \\
\left(\mathrm{kN} / \mathrm{m}^{2}\right)\end{array}$ & 508 & 2402 & 20000 \\
\hline Poisson's ratio $v$ & 0.352 & 0.331 & 0.330 \\
\hline Cohesion $\mathrm{c}_{\text {ref }}\left(\mathrm{kN} / \mathrm{m}^{2}\right)$ & 8.8 & 11.0 & 10 \\
\hline Friction angle $(0)$ & $3^{0} 14^{\prime}$ & $5^{0} 58^{\prime}$ & $25^{0}$ \\
\hline Dilatancy angle $(0)$ & 0 & 0 & 0 \\
\hline
\end{tabular}

The properties of the DCM columns are tested from the $\mathrm{q}_{\mathrm{u}}$ determination test and references to the documents regarding the properties of DCM columns: CDIT (2002) [4] shows that specific weight of the soil mixed with cement increases from $3 \%$ to $15 \%$. From sample compression tests, Young's modules are taken as $\mathrm{E}_{50}=(50 \div 63) \mathrm{q}_{\mathrm{u}}$. Poisson's ratio according to Niina et al. (1977) [17] is proposed from 0.15 to 0.35 . The resulted parameters are shown in Table 3 .

Geotextile is simulated by Geogrid element with $\mathrm{EA}=2500 \mathrm{kN} / \mathrm{m}$. 
Table 3. Parameters of DCM columns

\begin{tabular}{|c|c|}
\hline Parameters & Value \\
\hline Material model & Mohr-Coulomb \\
\hline Type of behavior & Un-drained \\
\hline Unit weight $\gamma_{\text {unsat }}\left(\mathrm{kN} / \mathrm{m}^{3}\right)$ & 11.15 \\
\hline Saturated unit weight $\gamma_{\text {sat }}\left(\mathrm{kN} / \mathrm{m}^{3}\right)$ & 18.40 \\
\hline Horizontal permeability, $\mathrm{k}_{\mathrm{x}}(\mathrm{m} /$ day $)$ & $10^{-7}$ \\
\hline Vertical permeability, $\mathrm{k}_{\mathrm{y}}(\mathrm{m} /$ day $)$ & $10^{-7}$ \\
\hline Young's modules, $\mathrm{E}\left(\mathrm{kN} / \mathrm{m}^{2}\right)$ & 100000 \\
\hline Poisson's ratio $v$ & 0.333 \\
\hline Cohesion $\mathrm{c}_{\text {ref }}\left(\mathrm{kN} / \mathrm{m}^{2}\right)$ & 175 \\
\hline Friction angle $\left({ }^{0}\right)$ & 30 \\
\hline Dilatancy angle $\left({ }^{0}\right)$ & 0 \\
\hline
\end{tabular}

Table 4. Calculation phases

\begin{tabular}{|c|c|c|c|c|}
\hline Phase & Item & Cal. type & Loading input & Time \\
\hline Initial & N/A & $\mathrm{N} / \mathrm{A}$ & N/A & 0 day \\
\hline 1 & Construction of DCM columns & Plastic & $\begin{array}{l}\text { Staged construction } \\
\text { Click DCM columns }\end{array}$ & 5 days \\
\hline 2 & Construction of geotextile & Plastic & $\begin{array}{l}\text { Staged construction } \\
\text { Click geotextile } \\
\end{array}$ & 5 days \\
\hline 3 & $\begin{array}{c}\text { Construction of road emb. fill } \\
1 \text { of } 1.0 \mathrm{~m} \text { thickness }\end{array}$ & Consolidation & $\begin{array}{c}\text { Staged construction } \\
\text { Click road emb.fill } 1 \\
\end{array}$ & 5 days \\
\hline 4 & For consolidation & Consolidation & Staged construction & 15 days \\
\hline 5 & Stability, FS4 & $\begin{array}{c}\mathrm{Phi} / \mathrm{c} \\
\text { reduction }\end{array}$ & Incremental multipliers & 0 day \\
\hline 6 & $\begin{array}{c}\text { Construction of road emb. fill } \\
2 \text { of } 1.0 \mathrm{~m} \text { thickness }\end{array}$ & Consolidation & $\begin{array}{c}\text { Staged construction } \\
\text { Click road emb.fill } 2 \\
\end{array}$ & 5 days \\
\hline 7 & For consolidation & Consolidation & Staged construction & 15 days \\
\hline 8 & Stability, FS7 & $\begin{array}{c}\mathrm{Phi} / \mathrm{c} \\
\text { reduction }\end{array}$ & Incremental multipliers & 0 day \\
\hline 9 & $\begin{array}{c}\text { Construction of road emb. fill } \\
3 \text { of } 1.0 \mathrm{~m} \text { thickness }\end{array}$ & Consolidation & $\begin{array}{c}\text { Staged construction } \\
\text { Click road emb. fill } 3 \\
\end{array}$ & 5 days \\
\hline 10 & For consolidation & Consolidation & Staged construction & 15 days \\
\hline 11 & Stability, FS10 & $\begin{array}{c}\mathrm{Phi} / \mathrm{c} \\
\text { reduction }\end{array}$ & Incremental multipliers & 0 days \\
\hline 12 & $\begin{array}{c}\text { Construction of road emb. fill } \\
4 \text { of } 1.0 \mathrm{~m} \text { thickness } \\
\end{array}$ & Consolidation & $\begin{array}{c}\text { Staged construction } \\
\text { Click road emb.fill } 4 \\
\end{array}$ & 5 days \\
\hline 13 & For consolidation & Consolidation & Staged construction & 15 days \\
\hline 14 & Stability, FS13 & $\begin{array}{c}\mathrm{Phi} / \mathrm{c} \\
\text { reduction }\end{array}$ & Incremental multipliers & 0 day \\
\hline 15 & $\begin{array}{l}\text { Construction of road emb. } \\
\text { fill } 5 \text { of } 1.0 \mathrm{~m} \text { thickness }\end{array}$ & Consolidation & $\begin{array}{c}\text { Staged construction } \\
\text { Click road emb. fill } 5 \\
\end{array}$ & 5 days \\
\hline 16 & For consolidation & Consolidation & Staged construction & 15 days \\
\hline 17 & Stability, FS16 & $\begin{array}{c}\mathrm{Phi} / \mathrm{c} \\
\text { reduction }\end{array}$ & Incremental multipliers & 0 day \\
\hline 18 & Loading $20 \mathrm{kN} / \mathrm{m} 2$ & Plastic & $\begin{array}{l}\text { Staged construction } \\
\text { Click loading }\end{array}$ & 5 days \\
\hline 19 & Stability, FS18 & $\begin{array}{c}\mathrm{Phi} / \mathrm{c} \\
\text { reduction }\end{array}$ & Incremental multipliers & 0 day \\
\hline \multicolumn{4}{|c|}{ Total } & 115 days \\
\hline
\end{tabular}

\subsection{Calculation}

Each model is analyzed in various phases: Construction of DCM columns, construction of geotextiles, road embankment fill and loading as shown in Table 4.

Plastic calculation is used to compute elastic-plastic deformation. It is used when analyzing the destructivity and stability of a to-be-analyzed object. The plastic calculation does not take into account the time factor when the pore water pressure is released, and is therefore not suitable for settlement analysis of the ground of low permeability. 
Consolidation Analysis: Saturated soil must be drained when settlement increases. For the low permeability soil such as clay, this process takes a long time and is very important to be considered when analyzing settlement. That is the main phenomenon in consolidation calculation. This calculation is therefore suitable for the analysis of settlement over time for water- saturated soils and low permeability soils.

Safety Analysis ( $\varphi$ reduction): For safety analysis, Plaxis included a type of calculation called PHI-C reduction. This is a calculation of plasticity, in which the soil strength parameters and interface are gradually reduced until failure. Safety coefficient for an object is calculated by dividing the transient strength by the failure strength.

Phreatic level is located at the depth of $-1.0 \mathrm{~m}$. Closed consolidation boundary is registered for the left and right boundaries of the problem. Generation of water pressures is made by selecting generate water pressures based on Phreatic level.

\subsection{Results}

The calculation results are shown in Figs 6-15.

Figure 6 shows that the ground fails to bear the load of the first embankment (total displacement is $508.45 \mathrm{~mm}$ ). However, when the soft ground consolidated with DCM columns combined with geotextiles total displacement is $120.18 \mathrm{~mm}$ under the 5th embankment and with the loads of vehicles (Figure 7), the maximum horizontal displacement is $95.65 \mathrm{~mm}$ (Figure 8) and the maximum vertical displacement at the center of the roadbed is 120.18 $\mathrm{mm}$ (Figure 9).

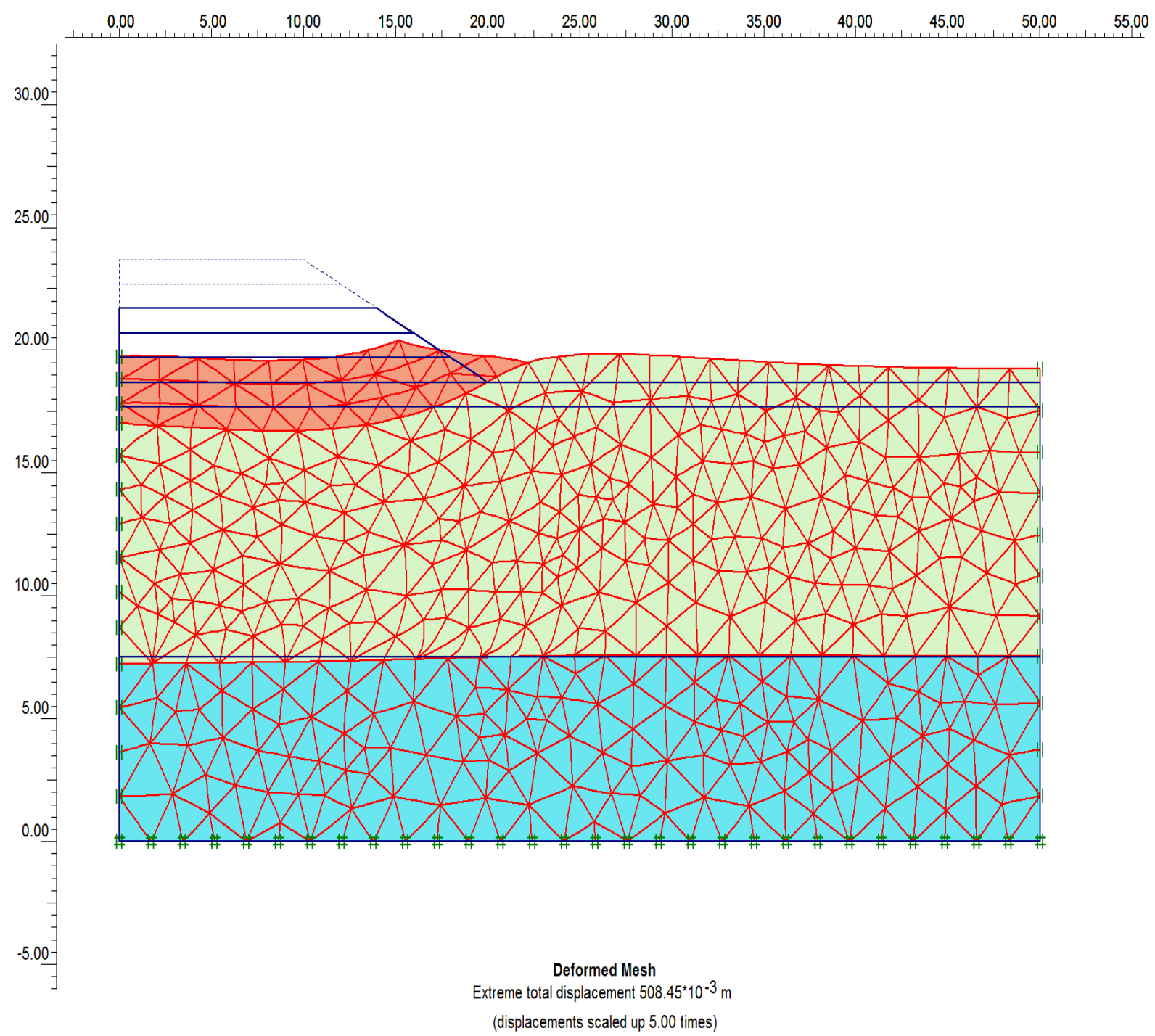

Figure 6. The displacement of the soft ground without consolidation 


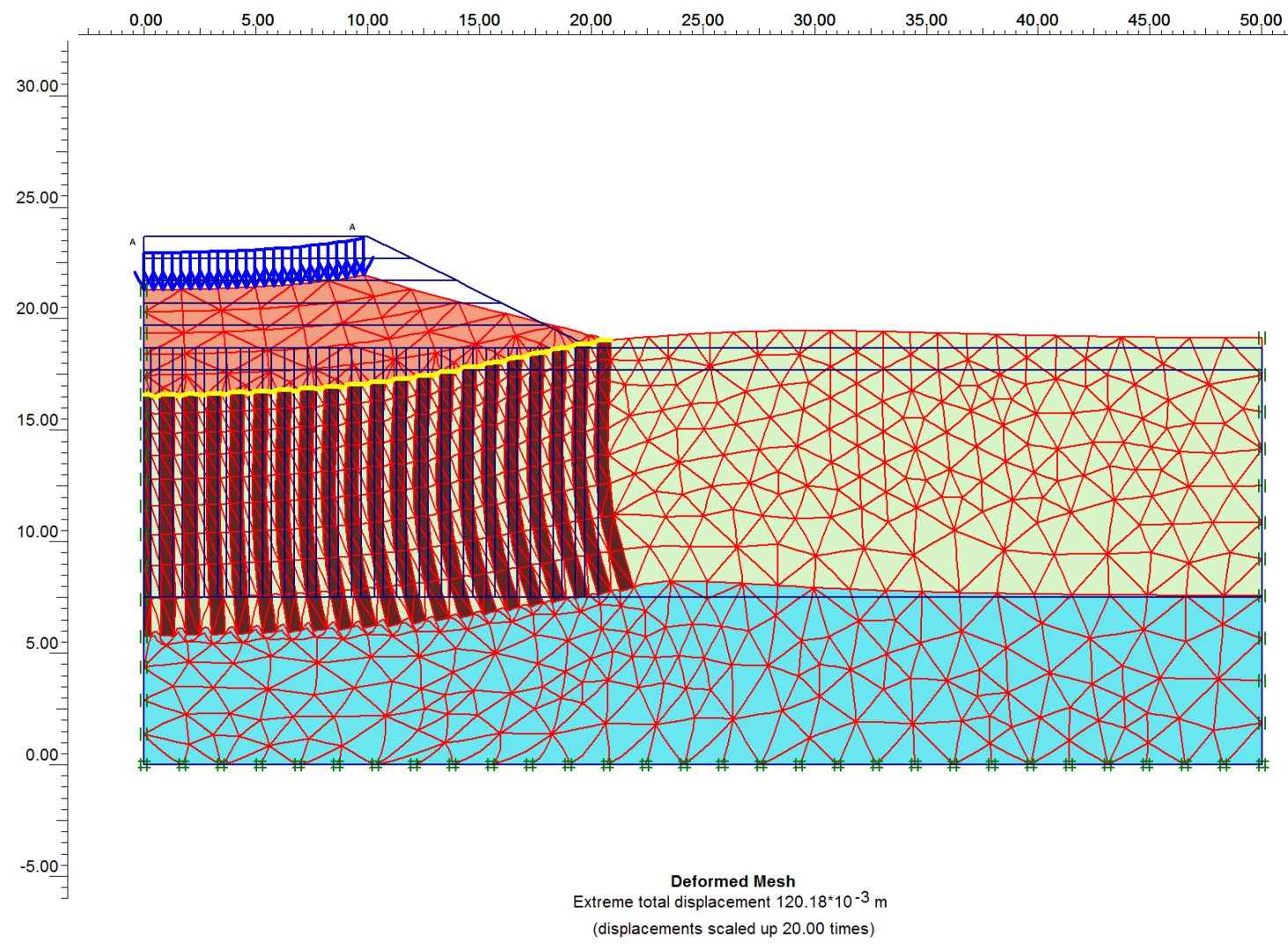

Figure 7. The soft ground displacement with consolidation after 115 days

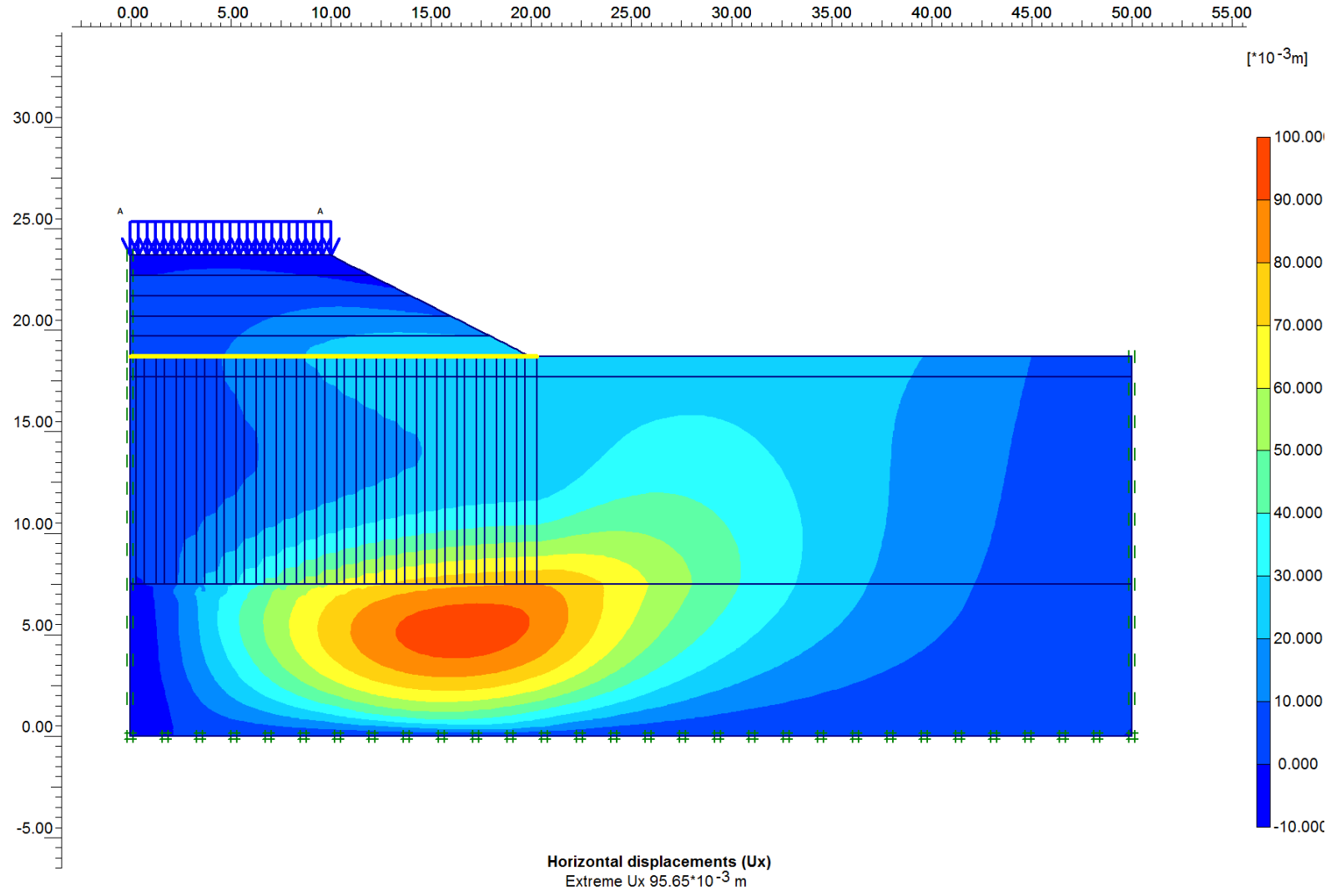

Figure 8. Horizontal displacement of the soft ground with consolidation 


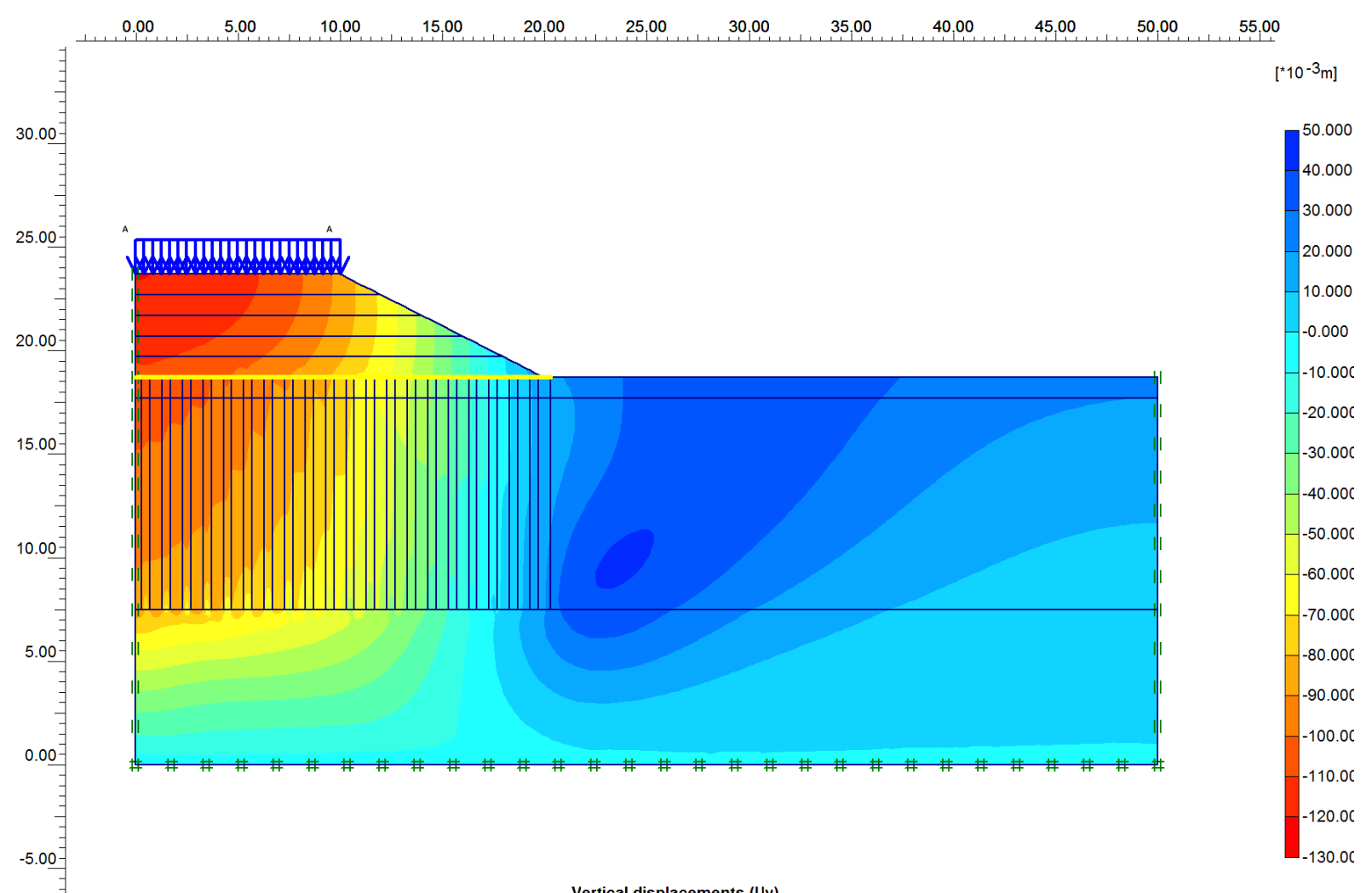

Figure 9. Vertical displacement of the soft ground with consolidation

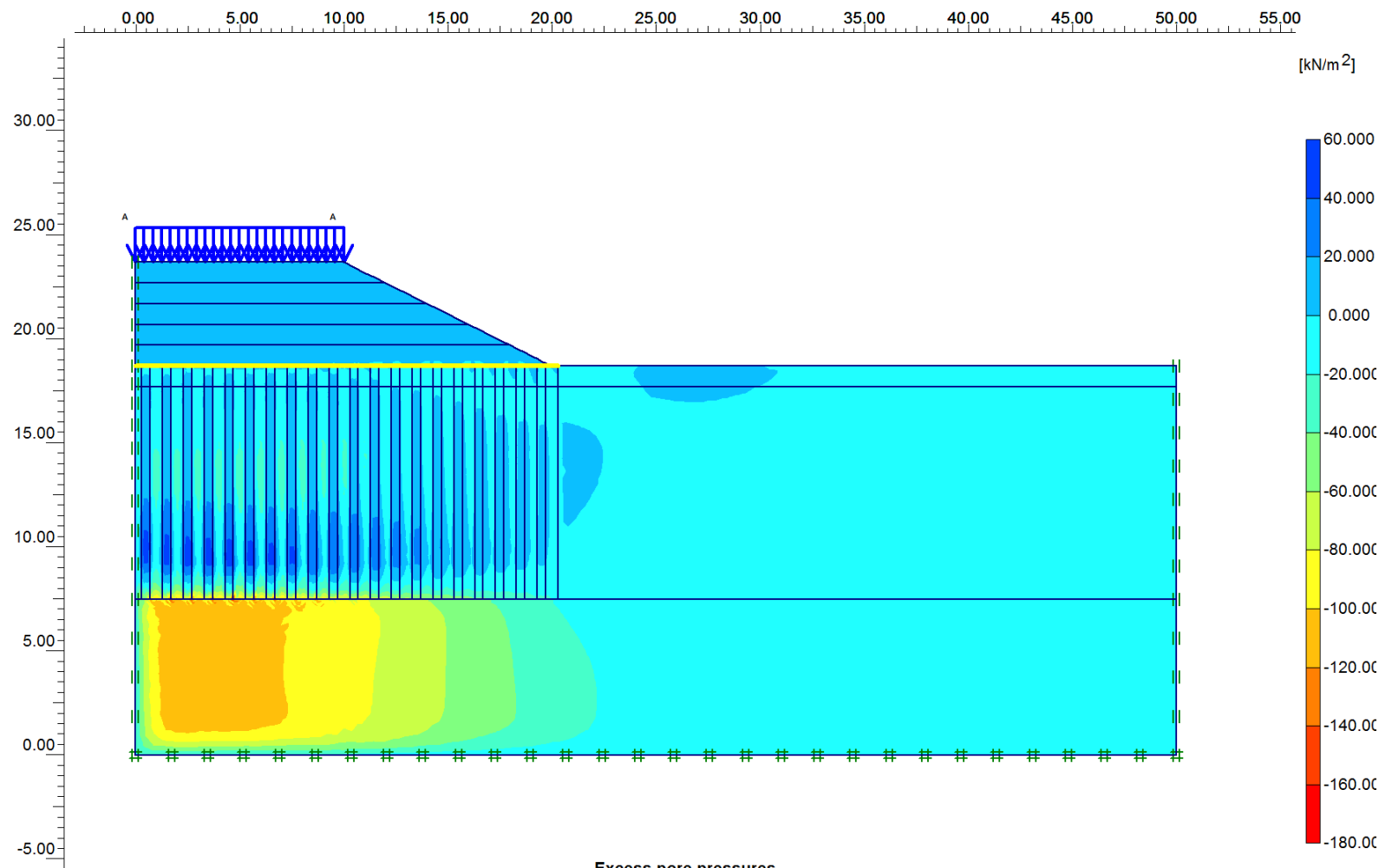
Excess pore pressures
Extreme excess pore pressure $-164.49 \mathrm{kN} / \mathrm{m}^{2}$

(pressure $=$ negative $)$

Figure 10. Residual pore water pressure 
When simulating the soft ground consolidated with DCM columns and geotextiles, the surplus pore water pressure is also taken into account and the surplus pore water pressure of this study reaches $164.49 \mathrm{kN} / \mathrm{m} 2$ (Figure $10)$.
Figures 11 and 12 show the distribution of the effective and total stresses on the DCM columns and on the soft ground composing such columns. The maximum effective stress $\left(200.063 \mathrm{kN} / \mathrm{m}^{2}\right)$ is twice less than the maximum total stress $\left(402.73 \mathrm{kN} / \mathrm{m}^{2}\right)$.

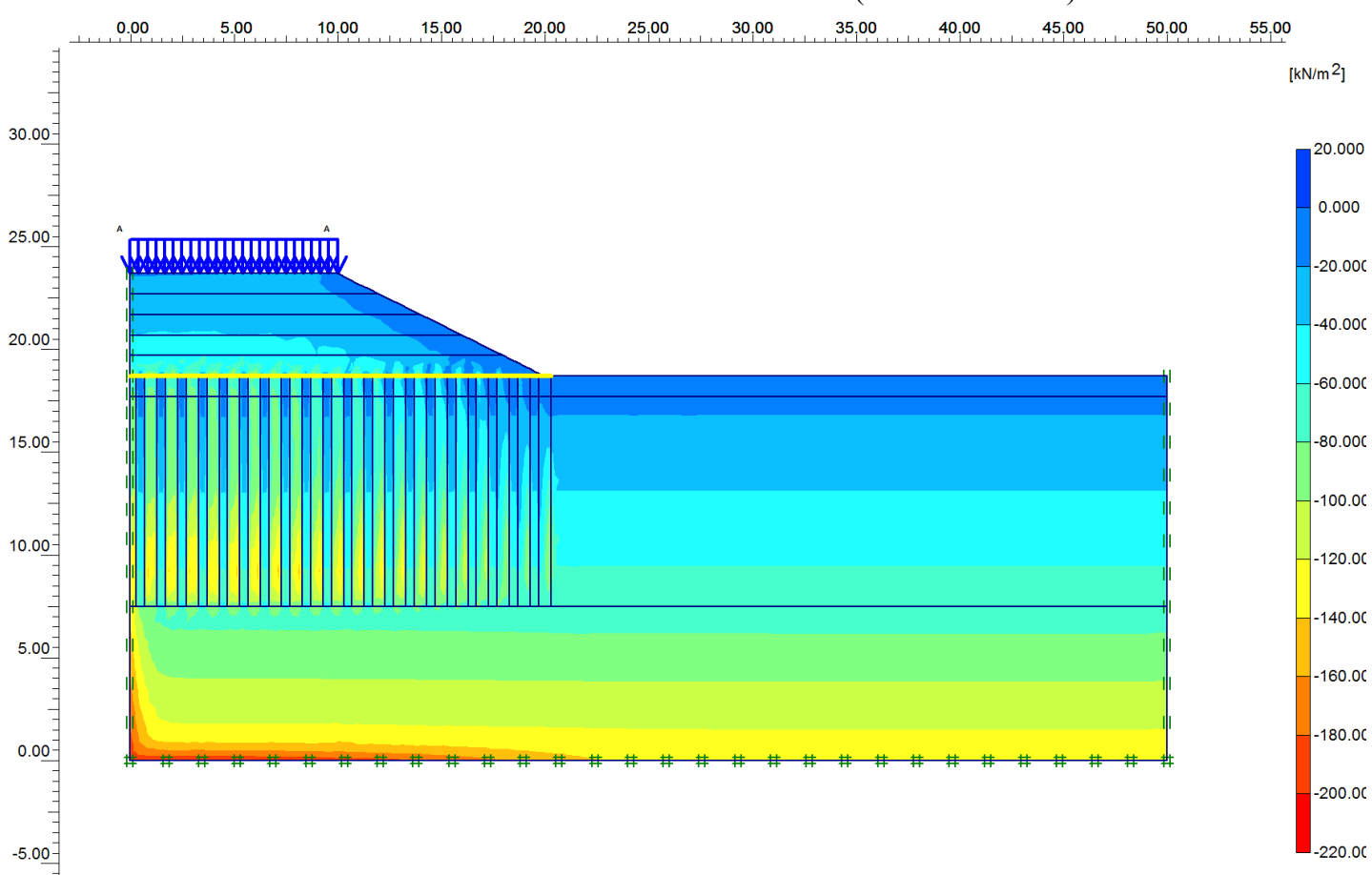

Effective mean stresses
Extreme effective mean stress $-200.06 \mathrm{kN} / \mathrm{m}^{2}$

Figure 11. Effective stress distribution in the consolidated soft ground

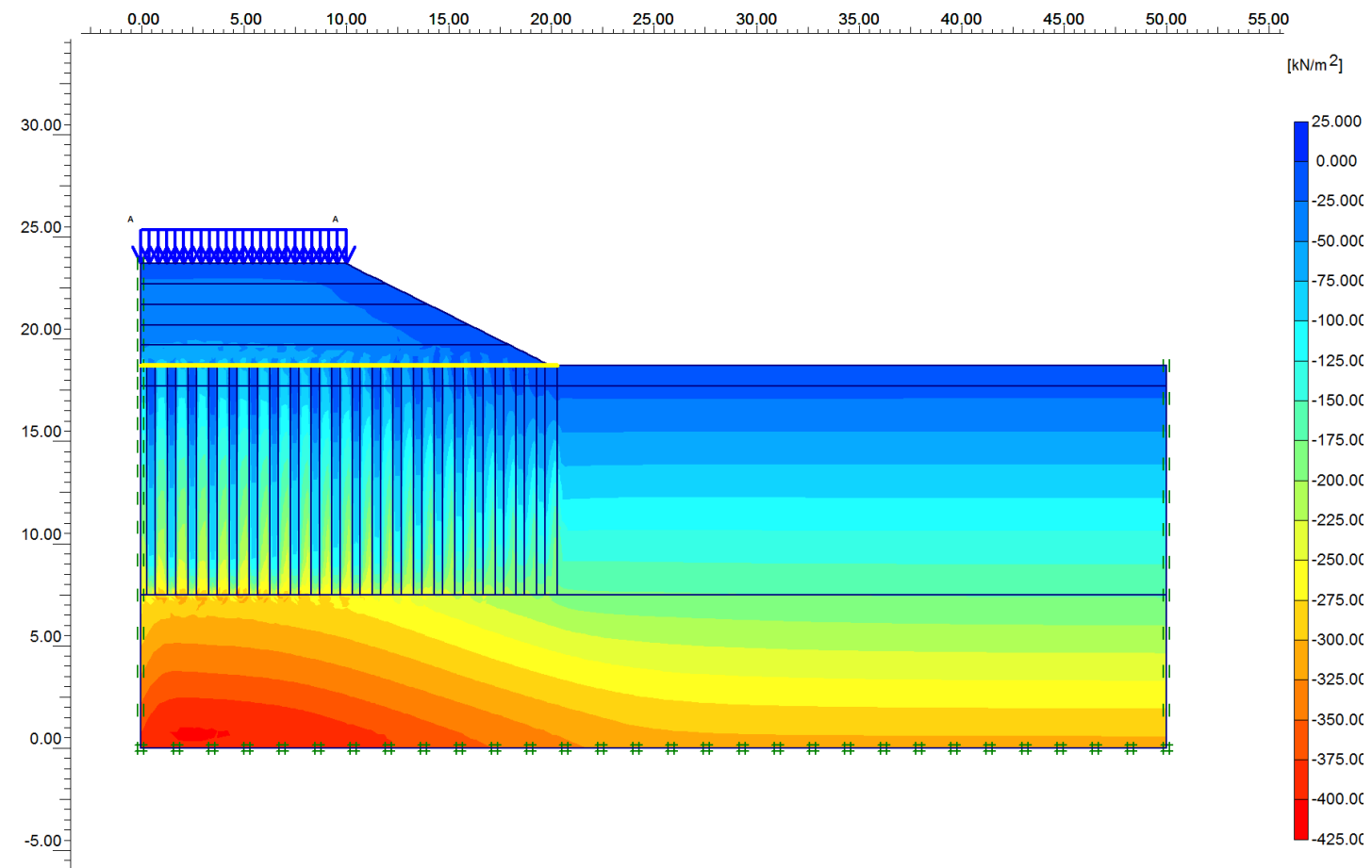

Mean stresses

Extreme mean stress $-402.73 \mathrm{kN} / \mathrm{m}^{2}$

Figure 12. Total stress distribution in the consolidated soft ground 


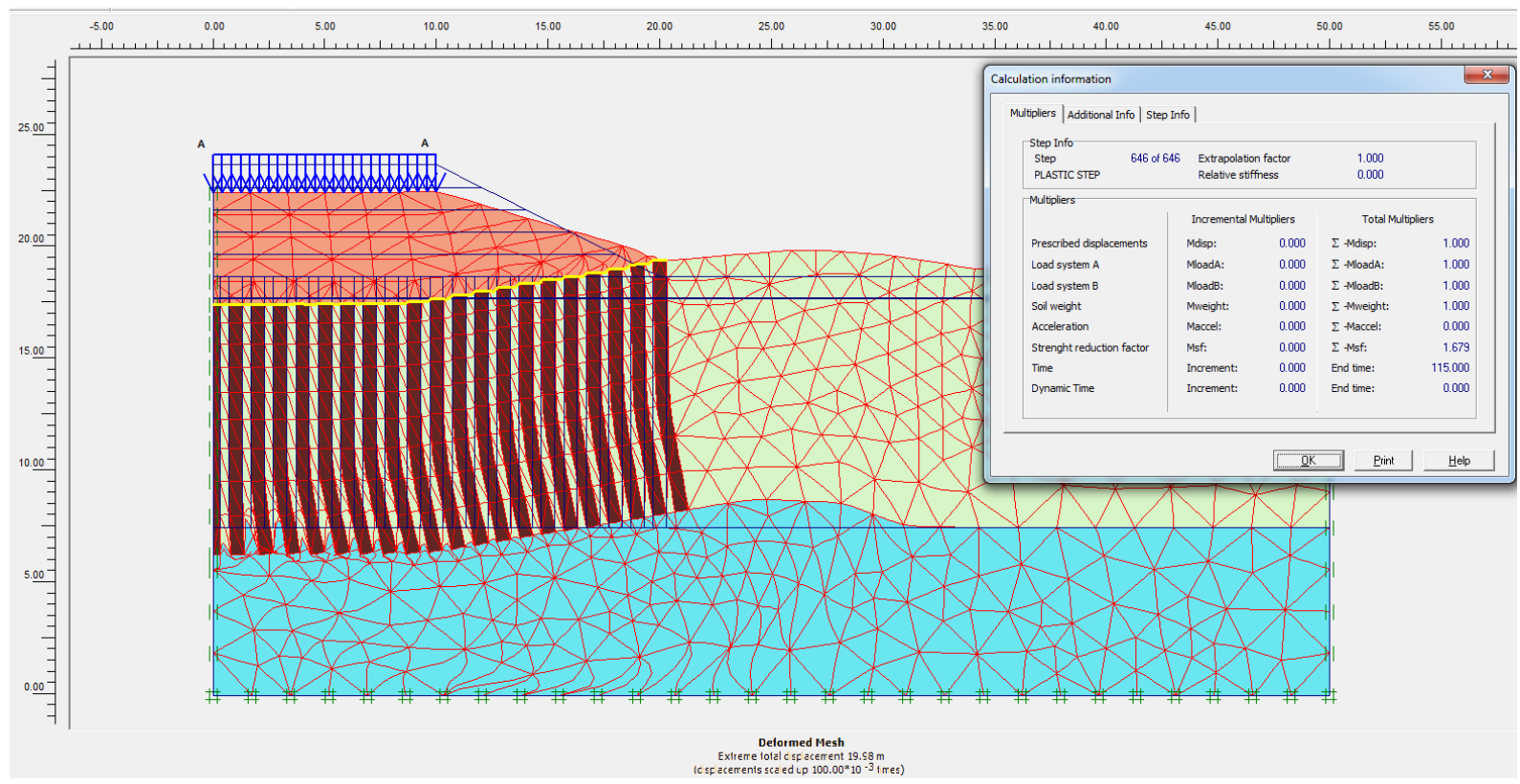

Figure 13. Stability coefficient of the consolidated soft ground

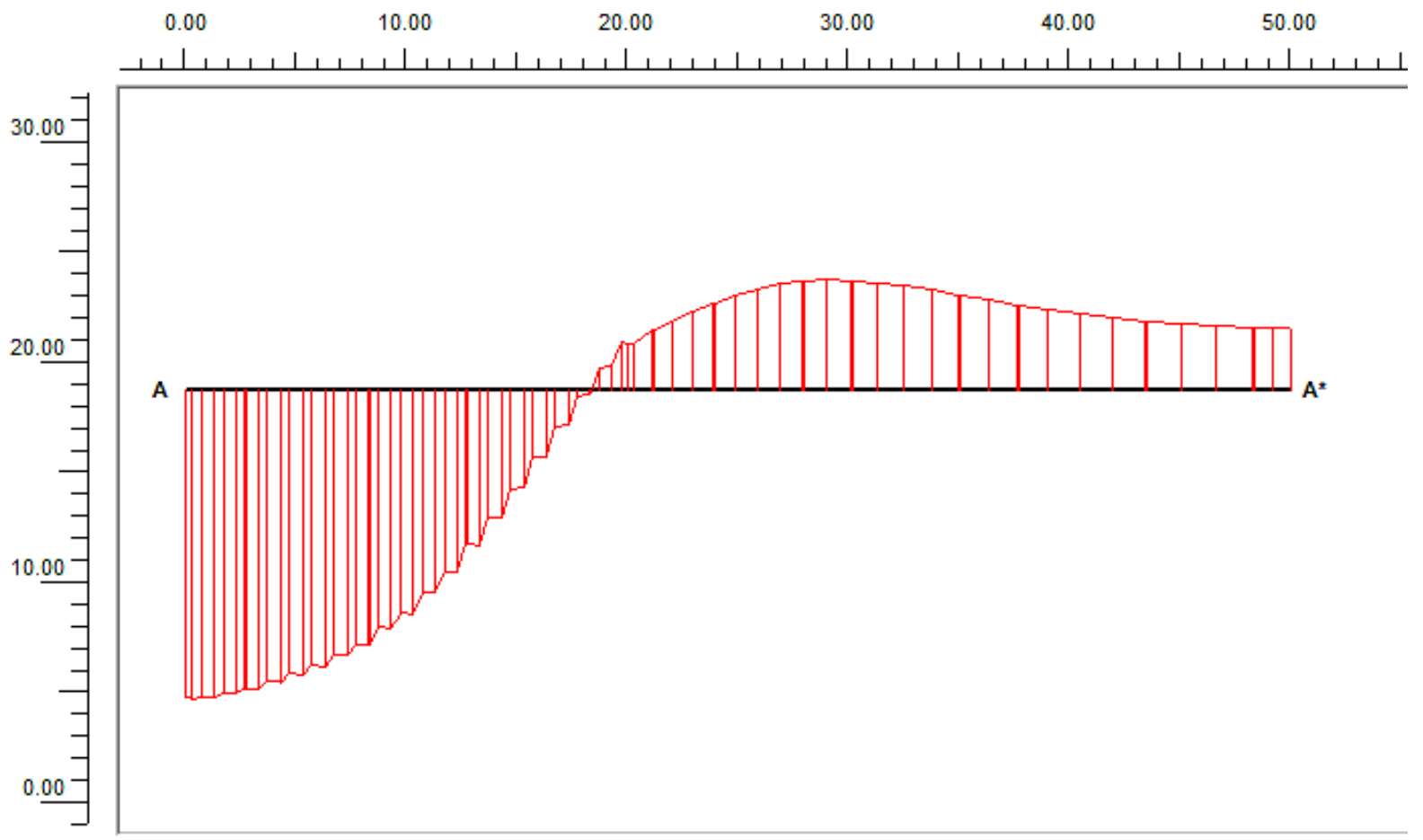

Vertical displacements Uy

Exireme Uy $-105.88^{*} 10^{-3} \mathrm{~m}$

Figure 14. Vertical displacement at the tip of DCM columns

Figure 13 shows that the resultant parameters of the Plaxis software and the simulation results give the coefficient of stability of $\sum-\mathrm{Mfs}=1.679$ that is greater than 1 , indicating that the soft ground is in stable condition and has enough load bearing capacity after consolidation.
The soil cement columns near the road center experience the greatest displacements, the ones far from the center experience smaller displacements, and they tend to uplift (Figure 14). Figure 15 shows that the stress distribution at the tips of DCM column is greater than that at the ground around the column. 


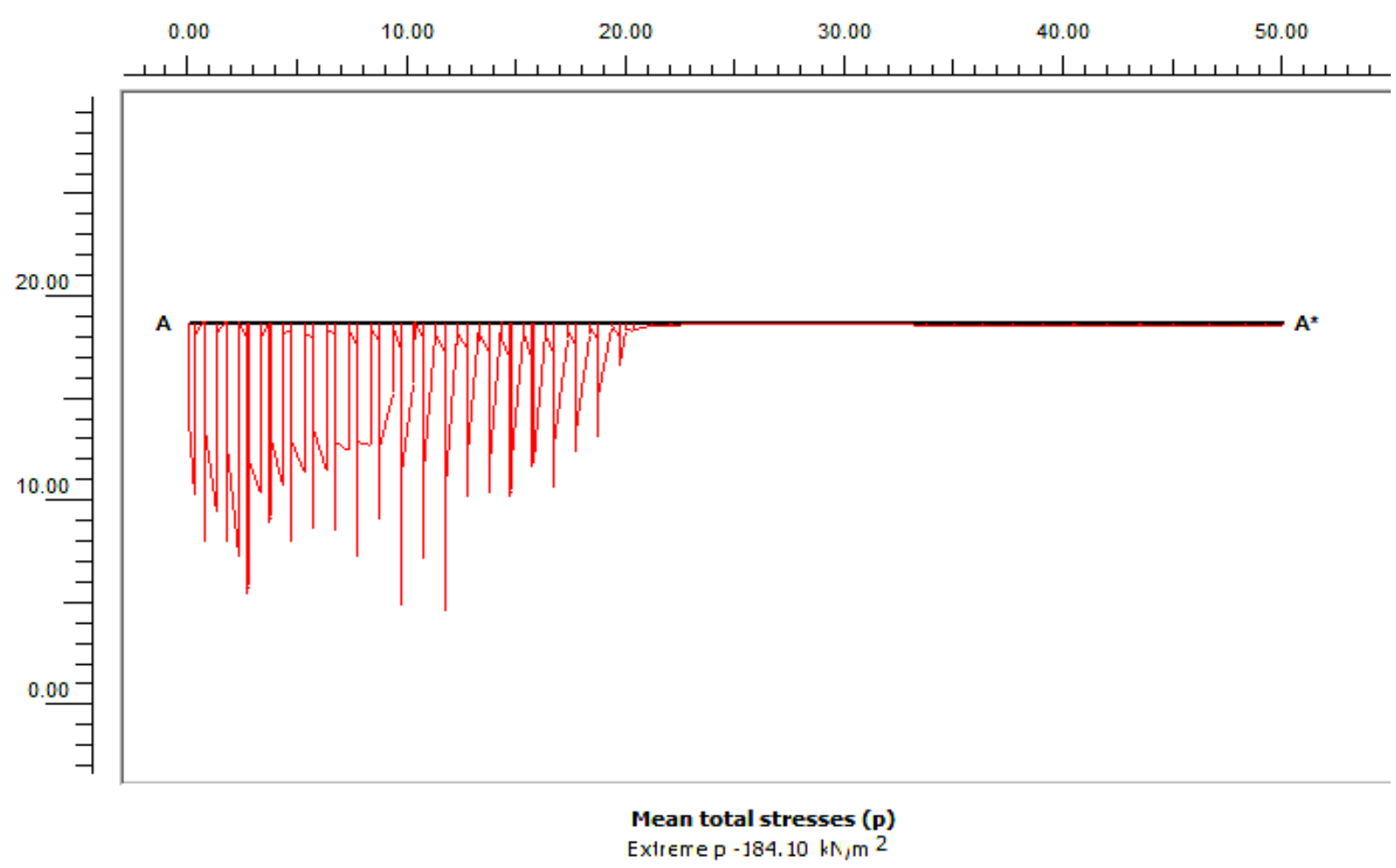

Figure 15. Stress distribution at the tip of DCM columns

\subsection{Discussion}

When the ground is not consolidated, it will fail when the 3 rd embankment is built with the settlement of $0.508 \mathrm{~m}$. When the ground is consolidated with DCM columns of $0.6 \mathrm{~m}$ diameter, $11.2 \mathrm{~m}$ length and $1.0 \mathrm{~m}$ center-to-center spacing, the settlement is only $0.120 \mathrm{~m}$ and the stability coefficient becomes 1.679 .

Stress concentration factor according to the simulation model is $\mathrm{n}=5.2$.

With finite element method, it is possible to simulate the problem of consolidating soft ground with DCM columns.

The calculation method is suitable for estimating the load concentrated on the column tip and the load distributed on the soft ground between the DCM columns with geotextiles in soft soil of Mekong Delta. The addition of the reinforcement layer on the tip of the column has a significant effect to reduce the stress to soft soil. According to the results obtained from the above analysis, the SRR is reduced where the reinforcement layer is added on the tip of the column. The survey can evaluate the reduction rate of settlement of the ground surface before and after consolidation in respect to elastic parameters of soils, columns and the sizes of columns.

\section{Conclusions}

The finite element method can simulate the problem of the soft ground consolidated with DCM columns. This method can allow researchers to calculate the residual stress and pore pressure at any point on the ground.

The DCM column technology is effectively applied for the treatment of the embankments on soft ground and the works with short-time construction, remaining small settlement and rapid soil consolidation. Calculation results help prepare the suitable design for soft soil reinforced with DCM columns combined with geotextiles in Tien Giang.

After the soft ground is reinforced with DCM columns, the settlement of the ground surface is reduced by 4.2 times $(76 \%)$.

Simulation results show that there is stress concentration phenomenon at the tips of columns in the geological conditions of the Mekong Delta.

There are many technical solutions for treatment of soft ground under road embankment and each solution has its own advantages and disadvantages. Applying which solution should depend on the conditions such as geological structure of the ground and the acting loads. The solution in this study is only given from the technical aspect not from the economical one. The solution of soft ground consolidation with DCM columns combined with geotextiles is found to be effective for the geological conditions of the Mekong Delta and the regions with similar properties.

\section{Recommendations}

It is recommended to apply problem model to study the 
consolidation of soft ground by DCM columns, determine the stress state, limit stress and calculate the transient settlement of the consolidated surface.

Consolidating soft ground with DCM columns is a technical solution, which depends on many factors, so its approaches are very various such as research on reinforcing materials, technological equipment, etc. Simulation results of the study show that the improvement of the practicality of the study may be obtained by additional studies on the effects of the buffer layer, the on-column embankments and the stiffness of the column on the stress variation in the ground-column system.

\section{REFERENCES}

[1] 22TCN262-2000. The specification of surveying and designing the motorway sub-grade on soft ground, Ministry of Transpot, Vietnam, 2000.

[2] Ahmed Farouk, Marawan M. Shahien. Ground improvement using soil-cement columns: Experimental investigation", Alexandria Engineering Journal, Vol.52, pp. 733-740, 2013.

[3] Bui Huu Hiep. Study on behavior of soft ground stabilized by deep cement mixing columns combined geotextiles under road embankment at Cai Lay district - Tien Giang province, Journal of Industrian Economic, Long An University of Economics and Industry, 2020.

[4] Coastal Development Institute of Technology-CDIT. The Deep Mixing Method: Principle, Design and Construction, A.A. Balkema: The Netherlands, 2002.

[5] Dolrerdee Hormdee1, and Piyoros Jirawattana. Bearing capacity and compressibility on improved loess by compaction and cement admixture, International Journal of GEOMATE, Vol.19, Issue 73, pp. 134-140, 2020.

[6] EuroSoilStab. Development design and construction methods to stabilize soft organics soils, Design Guide Soft Soil Stabilization, CT 97-0351, Project No.: BE 96-3177.

[7] Engineering Geological Report, Project at Chau Thanh district - Tien Giang province. Thanh Phu TG one member limited company, 2018.

[8] Hong-Son Nguyen, Yuji Adachi, Takuma Kizuki, Hiroyuki Maeba, Shinya Inazumi. Integration of information and communication technology (ICT) into cement deep mixing method, International Journal of GEOMATE, Vol.19, Issue 74, pp. 194-200, 2020.

[9] Le Van Nam, Nguyen Minh Tam and Nguyen Ngoc Thang, Study on using laboratory model to research for bearing capacity of soft ground improved by deep cement mixing columns due to embankment load with different montmorillonite, Vietnam Journal of Construction-Vietnam Ministry of Construction, Vol. 54, Issue 4, pp. 89-92, 2015.

[10] Tho L.X. Study on ensuring the stability of embankment on soft ground with the support of DCM columns, Engineering doctoral thesis, MADI University, Russia, 2011.

[11] Thang, N.N. Effect of montmorillonite content on the bearing capacity of soft ground improved by deep cement mixing columns, Doctoral thesis, Ho Chi Minh City University of Technology, 2017.

[12] Dat, N.Q. Study applied chemical grouting technology to protect the dyke in Ha Nam Province, Doctoral thesis, Academy for Water Resources, Ha Noi, 2013.

[13] Long N.T.B. The calculation method of deformation of soft soil masses improved by DCM columns takes into account shear strength of soft soil, Vietnam Journal of Construction-Vietnam Ministry of Construction, 2018.

[14] Trap N. et al. Stabilized soft ground by soil-lime columns, soi-cement columns and fabricated drainage reinforement, the research and application of scientific and technological progress 26-03-03-07. Vietnam Institute for Building Science and Technology, Ha Noi, 1985.

[15] Phuong N.T. Study of the fluence tides to the stress concentration ratio on the top piles in the soft ground treament solution by concrecte pile systems combine geotextle, Vietnam Journal of Construction-Vietnam Ministry of Construction Vol. 54, Issue 9, pp. 69-72, 2015.

[16] Hung N.V. Studied on solutions to improve the efficiency of soft soil treatment with DCM columns in the construction of embankments on soft ground, Doctoral thesis, University of Transport, Ha Noi, 2014.

[17] Niina, A. et al. Study on DMM using cement hardening agent (Part 1), Proc. of the 12th Japan National Conference on Soil Mechanics and Foundation Engineering, 1977, pp. $1325-1328$.

[18] Huynh P.V. A method for calculating stress-strain state in soft soil foundation reinforced by soil cement column in transport construction works, Doctoral thesis, Military Technical Academy, Ministry of National Defence, 2015.

[19] An P.V. Study on some factors affecting the load-bearing capacity of DCM columns to stabilize soft ground, Doctoral thesis, Academy for Water Resources, Ha Noi, 2012.

[20] Reza Ziaie Moayed, Ehsan Azini. Evaluation of numerical modeling of jet grouting design using in situ loading test", World Academy of Science, Engineering and Technology International Journal of Geotechnical and Geological Engineering Vol:14, No:6, 2020.

[21] Vietnamese Standard TCVN 9354 - 2012, Soils - In situ test methods for determination of deformation module by plate loading, 2012.

[22] Vietnamese Standard TCVN 9403-2012, Stabilization of soft soil- The soil cement column method, 2012.

[23] Terzaghi, K., Theoretical Soil Mechanics, Jonh Wily anh Sons, New York, 1943.

[24] Yemi Kehinde Ariye, KaileAbdulmalik A, and Akeem Olarenwaju Adigun. Soil-cement stabilization using papalanto to Sagamu road in Ogun State, Nigeria as Case Study", The International Journal of Engineering and Science (IJES), Vol.9, Issue 06, pp. 27-35, 2020. 